\title{
Notices and Announcements
}

\author{
Third International Conference on Visual Search \\ University of Nottingham \\ August 24-27, 1992
}

The Applied Vision Association, the Ergonomics Society, and the British Machine Vision Association and Society for Pattern Recognition are sponsoring the Third International Conference on Visual Search, to be held at the University of Nottingham, U.K., August 24-27, 1992.

This is the third in a series of international conferences devoted exclusively to all aspects of visual search processing. The meeting will encompass both human and machine vision approaches. The sessions will include (but not be limited to): attention and segmentation, eye movements, computer vision, search modeling, and applied aspects of search. There will also be a workshop, and the conference proceedings will be published.

For further information, contact: TICVS, Academic Radiology, University Hospital, Queens Medical Centre, Clifton Boulevard, Nottingham NG7 2UH, U.K. (Tel., 44(0)602 709442; FAX/ANSWERPhONe, 44(0)602 709140). 